\title{
Does location matter? A proposed methodology to evaluate neighbourhood effects on cardiac arrest survival and bystander CPR
}

\author{
Jason E. Buick, MSc ${ }^{* \dagger}$; Katherine S. Allan, MASc ${ }^{\ddagger \S}$; Joel G. Ray, MD, MSc ${ }^{\dagger \AA_{* *}}$; Alexander Kiss, $\mathrm{PhD}^{\dagger+\dagger}$; \\ Paul Dorian, MD, MSc ${ }^{* \S \mathbb{I}_{* *}}$; Peter Gozdyra, MA ${ }^{\mathbb{T}+t}$; Laurie J. Morrison, MD, MSc ${ }^{* \neq * * \neq \neq}$
}

\section{ABSTRACT}

Background: Traditional variables used to explain survival following out-of-hospital cardiac arrest (OHCA) account for only $72 \%$ of survival, suggesting that other unknown factors may influence outcomes. Research on other diseases suggests that neighbourhood factors may partly determine health outcomes. Yet, this approach has rarely been used for OHCA. This work outlines a methodology to investigate multiple neighbourhood factors as determinants of OHCA outcomes.

Methods: A retrospective, observational cohort study design will be used. All adult non-emergency medical service witnessed OHCAs of cardiac etiology within the city of Toronto between 2006 and 2010 will be included. Event details will be extracted from the Toronto site of the Resuscitation Outcomes Consortium Epistry-Cardiac Arrest, an existing population-based dataset of consecutive OHCA patients. Geographic information systems technology will be used to assign patients to census tracts. Neighbourhood variables to be explored include the Ontario Marginalization Index (deprivation, dependency, ethnicity, and instability), crime rate, and density of family physicians. Hierarchical logistic regression analysis will be used to explore the association between neighbourhood characteristics and 1) survival-to-hospital discharge, 2) return-of-spontaneous circulation at hospital arrival, and 3) provision of bystander cardiopulmonary resuscitation (CPR). Receiver operating characteristics curves will evaluate each model's ability to discriminate between those with and without each outcome. Discussion: This study will determine the role of neighbourhood characteristics in OHCA and their association with clinical outcomes. The results can be used as the basis to focus on specific neighbourhoods for facilitating educational interventions, CPR awareness programs, and higher utilization of automatic defibrillation devices.

\section{RÉSUMÉ}

Contexte: Les variables classiques ne permettent d'expliquer que $72 \%$ de la survie des malades à la suite d'un arrêt cardiaque extrahospitalier (ACEH), ce qui donne à penser que d'autres facteurs inconnus peuvent influer sur les résultats. Des recherches sur d'autres maladies semblent indiquer que des facteurs relatifs aux quartiers peuvent déterminer en partie les résultats cliniques. Pourtant, ce type de recherche a rarement été appliqué au contexte des $\mathrm{ACEH}$. Sera exposée ici une méthode visant à étudier différents facteurs relatifs aux quartiers et à les considérer comme des déterminants de résultats cliniques après un $\mathrm{ACEH}$.

Méthode: Pour ce faire, nous avons mené une étude de cohortes, rétrospective et observationnelle. Ont été retenus tous les adultes non rattachés à des services médicaux d'urgence, témoins d'un ACEH d'origine cardiaque, survenu dans la ville de Toronto entre 2006 et 2010. Les renseignements sur les faits ont été tirés du site Resuscitation Outcomes Consortium Epistry - Cardiac Arrest, une base de données déjà existante, située à Toronto, fondée sur une population composée de malades consécutifs ayant subi un $\mathrm{ACEH}$. Pour ce qui est de la localisation, des systèmes d'information géographique ont été utilisés pour lier les malades à des secteurs de recensement. Les variables relatives aux quartiers devant être examinées comprenaient I'Ontario Marginalization Index (indice de marginalisation de I'Ontario; privations, dépendance, origine ethnique et instabilité), le taux de criminalité et la densité des omnipraticiens. Une analyse de régression logistique hiérarchique a servi à étudier l'association entre les caractéristiques des quartiers et 1) la survie jusqu'au congé de l'hôpital; 2) le rétablissement spontané de la circulation sanguine à l'arrivée à I'hôpital; et 3) les manœuvres de réanimation cardiorespiratoire (RCR) appliquées par les passants. Des courbes caractéristiques de la performance des tests ont permis d'évaluer la capacité du

From the ${ }^{*}$ Rescu, Li Ka Shing Knowledge Institute, St. Michael's Hospital, Toronto, ON; Institute of Health Policy, Management and Evaluation, Faculty of Medicine, University of Toronto, ON; ҒInstitute of Medical Science, Faculty of Medicine, University of Toronto, ON; §Division of Cardiology, St. Michael's Hospital, Toronto, ON; ๆLi Ka Shing Knowledge Institute, St. Michael's Hospital, Toronto, ON; **Department of Medicine, University of Toronto, ON; †+Institute for Clinical and Evaluative Sciences, Sunnybrook Health Sciences Centre, Toronto, ON; and $¥ \neq D i v i s i o n$ of Emergency Medicine, Department of Medicine, University of Toronto, ON

Correspondence to: Jason Buick, Rescu, St. Michael's Hospital, 30 Bond Street, Toronto, ON M5B 1W8; Email: buickj@smh.ca; Dr. Laurie Morrison, Rescu, St. Michael's Hospital, 30 Bond Street, Toronto, ON M5B 1W8; Email: morrisonL@smh.ca 
modèle à discerner les variables qui comportaient ou non l'un ou l'autre des résultats d'intérêt.

Discussion: L'étude permettra de déterminer le rôle des quartiers dans le contexte des ACEH et d'établir des associations avec les résultats cliniques. Les faits dégagés pourront servir de base à la caractérisation des quartiers afin de faciliter les interventions éducatives, la mise en œuvre des programmes de sensibilisation à la RCR et I'utilisation accrue des appareils de défibrillation automatique.

Keywords: cardiopulmonary resuscitation, emergency medical services, geographic information systems, out-of-hospital cardiac arrest, residence characteristics

\section{INTRODUCTION}

Out-of-hospital cardiac arrest (OHCA) is a lifethreatening condition. Each year more than an estimated 300,000 people suffer an OHCA in North America. ${ }^{1}$ Despite recent advancements in prehospital and emergency care, the prognosis in North America remains poor, with on average less than $10 \%$ surviving, ${ }^{2,3}$ an unfortunate trend that has remained relatively stable over the past 30 years. $^{3}$

Although early cardiopulmonary resuscitation (CPR) and rapid successful defibrillation can improve survival rates to almost $40 \%,{ }^{4}$ it is highly dependent on numerous factors as represented by the links in the cardiac chain of survival, including immediate recognition of the event and activation of emergency medical services (EMS), early CPR, rapid defibrillation, effective advanced life support, and integrated post-cardiac arrest care. ${ }^{5}$ The Utstein variables were formulated as a template for cardiac arrest research and as a way to report the contribution of individual links in the chain. ${ }^{6}$ This template also highlights core data elements necessary for OHCA studies with the appropriate definitions (e.g., cardiac arrest witness status, EMS response time, bystander CPR, etiology). ${ }^{6}$ Researchers believed that these variables would account for most, if not all, aspects of survival.

In 2010, Rea et al. demonstrated that the Utstein variables accounted for only $72 \%$ of the nontraumatic EMS-treated survival ( $c$-statistic $=0.86)$, which suggests that other unknown factors may influence outcomes. ${ }^{7}$ But despite the vast amount of evidence implicating the Utstein variables as the main predictors of survival, few studies to date have investigated non-Utstein variables as predictors of survival and their influence on outcome variability. ${ }^{3,7}$

In OHCA, socioeconomic status (SES) ${ }^{8-14}$ and race/ ethnicity ${ }^{14-24}$ have been studied in relation to survivalto-hospital discharge and bystander CPR. These results are often contradictory and inconclusive, and these studies were limited in scope, only including one or two non-Utstein variables.
More recently, studies investigated the role of multiple factors on OHCA outcomes by expanding research from other disciplines, demonstrating that location can influence health outcomes. ${ }^{25}$ Ahn et al. used the Carstairs index as a composite measure to relate neighbourhood deprivation to cardiac arrest outcome in South Korea. They created deprivation indices for each census tract by averaging the z-standardized score across four census-derived indicators (overcrowding, unemployment among economically active men, percent in manual occupations, and lack of car ownership). Districts were then categorized into five quintiles based on level of deprivation. After adjusting for the Utstein variables, survival was significantly lower in the most deprived neighbourhood as compared to the least deprived. ${ }^{26}$ Sasson et al. evaluated collectively the influence of neighbourhood median household income and racial composition on the probability of receiving bystander CPR. ${ }^{13}$ They found that when compared to high-income Caucasian neighbourhoods, bystander CPR was less likely to occur in all neighbourhoods except those racially integrated with high median household incomes. ${ }^{13}$

Aside from a few prior studies, the majority of the literature has explored SES as a single variable (i.e., median household income or property tax value) with widely differing results. No study has been conducted in a Canadian setting, and none has collectively evaluated geographic, environmental, social, and cultural factors. Despite numerous examples within the social science and epidemiology literature where SES is treated as a complex, multidimensional construct encompassing varied socioeconomic and demographic factors, OHCA studies continue to use single SES descriptors in their analyses. This limitation might lead to inaccurate conclusions or mask potential differences in health-related outcomes. ${ }^{27}$ Furthermore, no previous study has investigated whether non-Utstein factors account for the remaining $28 \%$ of survival.

Given the previous limitations in the existing knowledge base, this study will investigate nontraditional 
determinants of OHCA outcomes in Toronto, Canada. In particular, neighbourhood factors will be used to investigate and potentially improve the understanding of what influences cardiac arrest outcomes.

\section{OBJECTIVES}

The objective of this study is to describe the methodology that will be used to investigate the role of neighbourhood factors as determinants of out-of-hospital cardiac arrest outcomes. The specific research questions are the following:

1. In OHCA patients, are patient home neighbourhood factors associated with either survival-to-hospital discharge or a return of spontaneous circulation (ROSC) at emergency department (ED) arrival? Does the addition of patient home neighbourhood factors to the Utstein variables improve the overall discrimination of those variables?

2. In OHCA patients, are arrest location neighbourhood factors associated with bystander CPR? Does the addition of arrest location neighbourhood factors to the Utstein variables improve the overall discrimination of those variables?

\section{METHODS}

\section{Study design}

A retrospective, observational cohort study design will be used to investigate the relationship between neighbourhood factors and cardiac arrest outcomes.

\section{Setting and study participants}

All patients who experience an OHCA within the catchment area of the University of Toronto's regional coordinating centre are entered into the Resuscitation Outcomes Consortium (ROC) Epistry-Cardiac Arrest registry, whose methodology has been previously described. $^{28}$ Briefly, ROC Epistry-Cardiac Arrest is a prospective population-based epidemiologic web registry of consecutive OHCA patients assessed by prehospital care providers. Prehospital care providers complete standardized documentation after each cardiac arrest, which is entered into ROC Epistry-Cardiac Arrest. Collected data include patient identifiers, call characteristics, prehospital interventions, and outcomes.
An extensive quality assurance program is in place to verify the accuracy of the study data. ${ }^{28}$

Primary care paramedics provide prehospital care in all regions and can perform CPR and semiautomated defibrillation. First responders from local fire departments and advanced care paramedics are tiered to all OHCA patients if and when available. Fire services in Ontario are equipped with automated external defibrillators and can perform basic life-support skills, while advanced care paramedics are able to gain intravenous access, provide advanced airway manoeuvres, and administer advanced life support (ALS) medications.

Inclusion and exclusion criteria for this study are in accordance with the Utstein template. ${ }^{6}$ All adult patients within the city of Toronto, age $20+$ years, who sustained a nontraumatic OHCA will be eligible for enrolment. A minimum age of 20 years will be used to be consistent with other literature ${ }^{7}$ and the Canadian census age category definitions. ${ }^{29}$ Any patient who met the criteria for obvious death (i.e., rigor mortis, lividity, decapitation, hemisection, or decomposition), who had a valid do-not-resuscitate-advanced directive, or whose OHCA was witnessed by paramedics will be excluded. Any patient who is missing adequate information for geocoding will also be excluded.

\section{Geocoding}

The patient's individual postal code will be used to determine his or her neighbourhood. ${ }^{30}$ Unfortunately, in health research, the use of the term neighbourboods (or community or area) is problematic because it has been broadly used to determine health, yet rarely has been consistently defined. ${ }^{25}$ Although there is no standard definition of neighbourbood within the ROC Epistry-Cardiac Arrest, census tracts will be used in this project to define neighbourhoods. Census tracts consist of relatively small homogeneous subsets of the population with about 2,500-6,000 people (Figure 1) ${ }^{31}$ and have been used previously when studying the role of location in OHCA outcomes. ${ }^{8,9,11-14,17,23,32}$

The patient's home address will be used in the analysis for survival-to-hospital discharge (and a ROSC at $\mathrm{ED}$ arrival) under the premise that survival is dependent on both the event and patient characteristics. The patient's home neighbourhood will be used as a surrogate for patient characteristics, because previous literature shows an association between home neighbourhood and cardiac risk factors, unhealthy behaviours, 


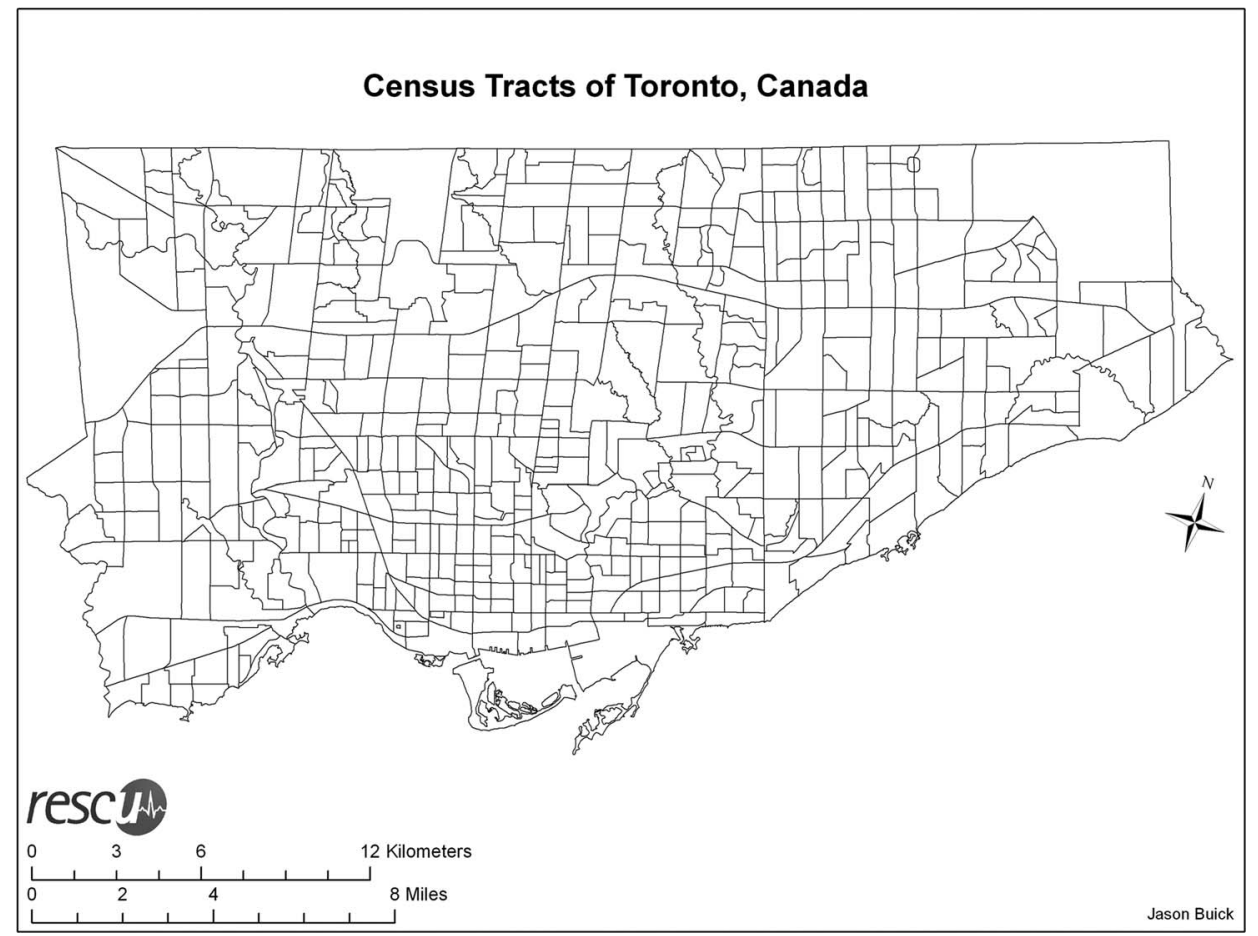

Figure 1. The 531 census tracts within the city of Toronto.

and overall health. ${ }^{33-45}$ The neighbourhood factors of the arrest location (i.e., the pickup address) will be used to study the effects on bystander CPR, because the emergency response (i.e., bystanders and EMS/paramedics) is contingent on the arrest location. ${ }^{10-13,46-48}$

A patient's home address is recorded as mailing address with street name, street number, and postal code, whereas the pickup address is recorded as a mailing address, with latitude and longitude coordinates and a Universal Transverse Mercator (UTM) value. ${ }^{28}$ Postal codes will be the preferred source for identifying addresses. Missing postal codes will be determined from the street address, ${ }^{49}$ the latitude/longitude, or UTM values $^{50}$ in a hierarchical fashion.

Postal codes will be linked to one of 531 nine-digit census tracts through a Postal Code Conversion File. ${ }^{30}$ Postal code conversion involves assigning each postal code to a census tract based on "best fit" dissemination area provided by Statistics Canada. In this approach, the postal code is assigned to the census tract that best covers the given postal code area. Each cardiac arrest patient will be assigned the characteristics of the associated census tract based on either the patient's home address or pickup address using geographic information system (GIS) mapping technology.

\section{Neighbourhood variables}

Neighbourhood variables to be included in the analysis include 1) the Ontario Marginalization Index (ON-Marg), 2) the crime rate, and 3) the density of family physicians. Each neighbourhood variable is expressed at the census tract level.

The ON-Marg is a geographically derived index used to study marginalization and highlight inequalities in various measures of health and social well being (Table 1). ${ }^{51}$ While previous indices relied heavily on aspects of material deprivation (e.g., income, car and home ownership, education), the ON-Marg reflects the change in society where new inequality measures may better reflect deprivation and health. Its dimensions include 1) residential instability, 2) dependency, 3) material deprivation, and 4) ethnic concentration. ${ }^{51}$ Crime rate is collected by the Centre for Research on Inner City Health at St. Michael's Hospital and is expressed as a number of violent crimes per 100,000 people at risk. This variable will be used to describe neighbourhood safety. ${ }^{52}$ The density of family physicians is collected by the Institute of Clinical and Evaluative Sciences and is expressed as a number of family physicians per 100,000 people. This will be 


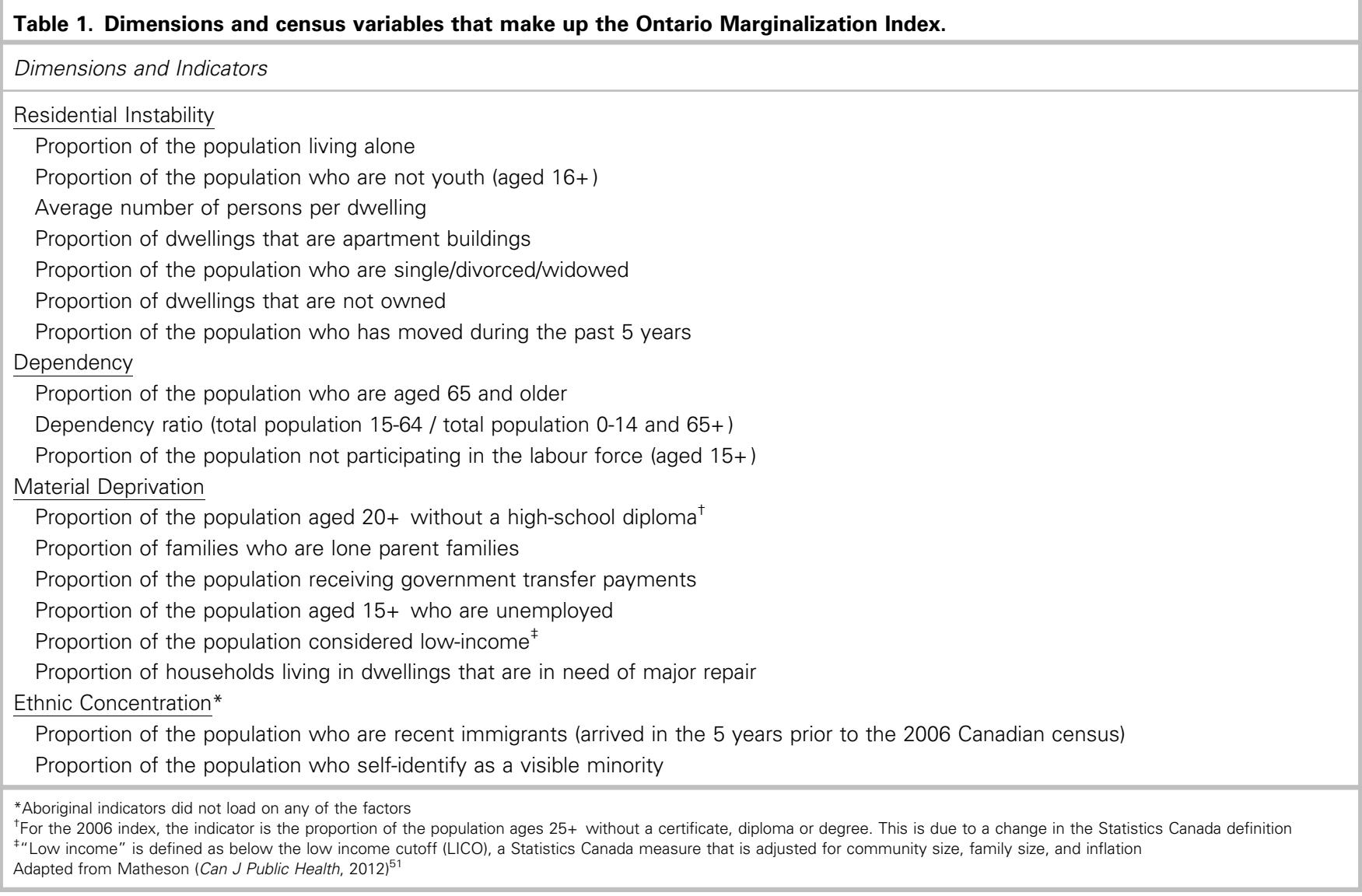

used as a surrogate measure of an individual's access to health care. ${ }^{53}$

Each of the six neighbourhood variables will be converted from its continuous form into quintiles, where quintile one will represent a disadvantaged neighbourhood and quintile five will represent an advantaged neighbourhood, to be consistent with previous literature that separates variables of interest by quintiles. $^{12,26,51}$ An analysis of variance (ANOVA) test will be used to ensure that each quintile is significantly different from one another across all variables.

\section{Statistical analysis}

Descriptive statistics will be used to assess the distribution of all variables. Continuous variables will be summarized as means and standard deviations, whereas categorical variables will be summarized as counts and percentages. The distribution of each continuous variable will be assessed for normality using graphical interpretation and the Shapiro-Wilk test.

Unadjusted bivariate analyses will be performed to assess for differences between the dependent and independent variables, using either a $t$-test for all continuous variables or an $\chi^{2}$ test for categorical variables. Model diagnostics will be performed on all models, and multicollinearity will be assessed using either the tolerance statistics or variance inflation factor (VIF). A tolerance of $<0.4$ or a VIF statistics of $>2.5$ would indicate multicollinearity.

Logistic regression analysis will determine relationships between the neighbourhood factors (in addition to the traditional Utstein variables) and the outcome measures. The regression model will adopt a hierarchical modelling approach using generalized estimating equations to capture variation within neighbourhoods as a random effect. Patients will be clustered based on census tract. This hierarchical approach also accounts for the lack of independence between variables, an assumption that would be violated if a single level modelling approach was used. Eight models will be analysed. One model (\#1) will contain only the Utstein (or individual variables). Six models (\#2-7) will include the Utstein variables and one neighbourhood factor. The final model (\#8) will include the Utstein variables and all neighbourhood factors (Table 2). Odds ratios (ORs) 


\begin{tabular}{l} 
Table 2. The variables that will be included in the model. \\
\hline Variables \\
\hline Utstein Variables
\end{tabular}

(with $95 \%$ confidence intervals) will be used to display the effect size of each independent variable. All statistical analyses will be carried out using SAS 9.3 (SAS Institute, Cary, NC). A two-sided $p$-value of $<0.05$ will be considered statistically significant.

Receiver operating characteristics curves will be used to measure the model's ability to discriminate between those with and without the outcome of interest (either survival-to-hospital discharge, a ROSC at ED arrival, or bystander CPR). ${ }^{54}$ The area under the curve (AUC) will be used to determine the probability that a patient will be correctly classified based on the outcome. Discrimination will be calculated as ([AUC - 0.5]/0.5).

\section{Choropleth maps}

Visual maps will be created using ArcGIS 10 (ESRI Canada Limited, Toronto, ON) to illustrate spatial patterns in the data and assist in disseminating the study findings to the general public who may not be familiar with statistical methodology. These visual maps also serve to drive further analysis and help generate hypotheses for additional studies. Data will be exported from SAS into a Microsoft Excel (Redmond, WA) spreadsheet and subsequently imported into ArcGIS 10. Unadjusted choropleth maps will be created using census tract frequency counts for the outcome measures and by quintiles for neighbourhood factors. Each map will be set in the North American 1983 datum UTM zone $17 \mathrm{~N}$ coordinate projection system.

\section{Sample size}

Because ROC Epistry-Cardiac Arrest is a prospective database, a power calculation will guide sample size calculations to define the smallest significant OR that could be detected, given the fixed sample size and outcome demographics. A 4-year period between April 2006 and March 2010 was used to derive an approximate sample size. An estimated 4,600 eligible patients have a home address in Toronto, of which approximately $18 \%$ had a ROSC at ED arrival, and $4.5 \%$ survived to hospital discharge. An estimated 5,100 eligible patients have a pickup address in Toronto, where approximately 40\% received bystander CPR. Given these sample sizes, this study is powered to detect a significant OR of 1.48 or greater for survival-tohospital discharge, an OR of 1.23 or greater for a ROSC at ED arrival, and an OR of 1.18 or greater for bystander CPR. All power calculations were carried out using PASS (Power Analysis and Sample Size [version 08.0.8], NCSS Statistical Software, Kaysville, UT).

\section{Research ethics}

Individual research ethics boards (REB) at all 37 destination hospitals within the catchment area approved the design and implementation of ROC Epistry-Cardiac Arrest. ${ }^{28}$ An institutional REB at St. Michael's Hospital provided approval for all retrospective studies using the ROC Epistry-Cardiac Arrest database. This study was also approved by the University of Toronto REB, which governs research performed by graduate students at academic hospitals associated with the University of Toronto.

\section{DISCUSSION}

To our knowledge, this will be the first Canadian study to investigate both traditional and nontraditional factors for OHCA outcomes. Although this study will not directly change clinical practice, it will help advance the understanding of a public health concern that kills over 90\% of Canadians who experience an OHCA. Provided that differences are observed, this study will also highlight the role of neighbourhood inequalities in explaining differences in survival. The results of this study will be of interest to resuscitation researchers, physicians, city planners, and policymakers because it may lead to the implementation of policy and procedures to optimize the delivery of care for specific neighbourhoods. It will also help decision makers plan future bystander CPR education programs and community-based intervention programs for areas with 
low rates of bystander CPR. Knowledge of neighbourhood risk factors for cardiac arrests and their association with population demographics could be helpful for treating and counseling individual patients, but also for planning EMS system response and community-wide health programs that will aid the largest number of citizens. It will also contribute to the existing health care system by identifying neighbourhoods that could potentially benefit from targeted policy and public health interventions. With collaboration between scientists, clinicians, policymakers, and elected city and health officials, there is the potential for improving individual and population health.

This study has many strengths. First, data will be extracted from a reputable, research quality registry of OHCA patients assessed by prehospital care providers. ${ }^{28}$ This registry has been used to answer OHCA-related questions, which have been incorporated into the current American Heart Association guidelines. ${ }^{5}$ The large sample size provides adequate power to detect small differences in outcomes. Second, the rigorous proposed analytic approach uses hierarchical modelling to account for patient and neighbourhood variables, and for patient clustering within neighbourhoods. Without the risk of multicollinearity, selecting a composite score will take into account the complex and multidimensional aspect of neighbourhood variables. ${ }^{27}$ Third, previous research almost exclusively reported ORs, which is useful for highlighting associations between predictor variables and outcomes, but is limited for identifying the discriminative ability of the independent variables. Although identifying causal relationships are not possible with this current design, this study will be the first to use receiver operating characteristics curves as a quantitative measure of a variable's discriminative ability for cardiac arrest outcomes. Furthermore, this study will demonstrate how GIS mapping technology could be adapted to explore a life-threatening public health concern. Its detailed methods section provides a step-by-step approach for using and adapting GIS technology to prehospital care. Combining cardiac arrest data with this technology provides a unique perspective about the association between locations and OHCA.

This study has some limitations. It relies on postal codes, UTM, or latitude/longitude to link patients with the neighbourhood factors. Location errors could result in misclassification, and then the patient would be linked to the incorrect census tract, which could introduce selection bias. An estimated 5\% of cases will be excluded due to incomplete geographic information, which is consistent with previous literature that has excluded between $3 \%$ and $15 \%$ of eligible cases. ${ }^{10-12,26}$ There are limitations associated with using census data. Neighbourhood characteristics may not be generalizable to individuals within a given census tract. Missing or incorrect data and low frequency counts could also alter conclusions. Although census data have their own limitations, they are one of the only population level datasets available to researchers. To prevent bias, Census Canada does follow up with any incomplete or unanswered questionnaires and adjusts the data for households who do not return a questionnaire. ${ }^{55}$

\section{CONCLUSIONS}

This paper highlights the methodology that will be used to evaluate the role of the neighbourhood as determinants of cardiac arrest outcomes, and whether those factors improve the discriminative ability of the Utstein variables.

Acknowledgements: The ROC is supported by a series of cooperative agreements to 10 regional clinical centers and one Data Coordinating Center (5U01 HL077863-University of Washington Data Coordinating Center, HL077865-University of Iowa, HL077866-Medical College of Wisconsin, HL077867University of Washington, HL077871-University of Pittsburgh, HL077872-St. Michael's Hospital, HL077873Oregon Health and Science University, HL077881-University of Alabama at Birmingham, HL077885-Ottawa Hospital Research Institute, HL077887-University of Texas SW Medical Center/Dallas, HL077908-University of California San Diego) from the National Heart, Lung and Blood Institute in partnership with the National Institute of Neurological Disorders and Stroke, U.S. Army Medical Research \& Material Command, The Canadian Institutes of Health Research (CIHR) - Institute of Circulatory and Respiratory Health, Defence Research and Development Canada, the Heart and Stroke Foundation of Canada, and the American Heart Association. The content is solely the responsibility of the authors and does not necessarily represent the official views of the National Heart, Lung and Blood Institute or the National Institutes of Health.

Competing interests: JEB holds a Jumpstart Resuscitation Master's Studentship from the Canadian Heart and Stroke Foundation. LJM is a U.S. National Institute of Health, Canadian Institute of Health Research, and Heart and Stroke Canada funded investigator within the Resuscitation Outcomes Consortium. She is a past chair and current member of the Science Subcommittee of Emergency Cardiac Care Committee of the American Heart Association and on the editorial board of the 2010 guidelines in resuscitation as the co-chair of the International Liaison Committee of Resuscitation Advance Life 
Support Taskforce in 2010 and current past chair of the ALS Taskforce for ILCOR 2015. She is the past chair of the Research and Policy Planning Advisory Committee and past board of directors member for Heart and Stroke Canada. The remaining authors have no competing interests relevant to this topic.

Authors' contributions: JEB conceived and designed the study under guidance from KSA, JGR, AK, PG, PD, and LJM. LJM oversaw data collection. JEB and LJM obtained ethics approval. JEB will be responsible for analysis and interpretation of the data under guidance from JGR, AK, and LJM. JEB and KSA drafted the manuscript, and all authors revised it for critically important intellectual content and approved the final version.

\section{REFERENCES}

1. Roger VL, Go AS, Lloyd-Jones DM, et al. Heart disease and stroke statistics-2012 update: a report from the American Heart Association. Circulation 2012;125(1):e2-e220.

2. Nichol G, Thomas E, Callaway CW, et al. Regional variation in out-of-hospital cardiac arrest incidence and outcome. 7AMA 2008;300(12):1423-31.

3. Sasson C, Rogers MA, Dahl J, et al. Predictors of survival from out-of-hospital cardiac arrest: a systematic review and meta-analysis. Circ Cardiovasc Qual Outcomes 2010;3(1): 63-81.

4. Weisfeldt ML, Sitlani CM, Ornato JP, et al. Survival after application of automatic external defibrillators before arrival of the emergency medical system: evaluation in the resuscitation outcomes consortium population of 21 million. 7 Am Coll Cardiol 2010;55(16):1713-20.

5. Travers AH, Rea TD, Bobrow BJ, et al. Part 4: CPR overview: 2010 American Heart Association Guidelines for Cardiopulmonary Resuscitation and Emergency Cardiovascular Care. Circulation 2010;122(18 Suppl 3):S676-84.

6. Jacobs I, Nadkarni V, Bahr J, et al. Cardiac arrest and cardiopulmonary resuscitation outcome reports: update and simplification of the Utstein templates for resuscitation registries. A statement for healthcare professionals from a task force of the international liaison committee on resuscitation (American Heart Association, European Resuscitation Council, Australian Resuscitation Council, New Zealand Resuscitation Council, Heart and Stroke Foundation of Canada, InterAmerican Heart Foundation, Resuscitation Council of Southern Africa). Resuscitation 2004;63(3):233-49.

7. Rea TD, Cook AJ, Stiell IG, et al. Predicting survival after out-of-hospital cardiac arrest: role of the Utstein data elements. Ann Emerg Med 2010;55(3):249-57.

8. Clarke SO, Schellenbaum GD, Rea TD. Socioeconomic status and survival from out-of-hospital cardiac arrest. Acad Emerg Med 2005;12(10):941-7.

9. Hallstrom A, Boutin P, Cobb L, et al. Socioeconomic status and prediction of ventricular fibrillation survival. Am 7 Public Health 1993;83(2):245-8.

10. Vaillancourt C, Lui A, De Maio VJ, et al. Socioeconomic status influences bystander CPR and survival rates for out-ofhospital cardiac arrest victims. Resuscitation 2008;79(3):417-23.

11. Mitchell MJ, Stubbs BA, Eisenberg MS. Socioeconomic status is associated with provision of bystander cardiopulmonary resuscitation. Prehosp Emerg Care 2009;13(4):478-86.
12. Sasson C, Keirns CC, Smith DM, et al. Examining the contextual effects of neighborhood on out-of-hospital cardiac arrest and the provision of bystander cardiopulmonary resuscitation. Resuscitation 2011;82(6):674-9.

13. Sasson C, Magid DJ, Chan P, et al. Association of neighborhood characteristics with bystander-initiated CPR. $N$ Engl 7 Med 2012;367(17):1607-15.

14. Sayegh AJ, Swor R, Chu KH, et al. Does race or socioeconomic status predict adverse outcome after out of hospital cardiac arrest: a multi-center study. Resuscitation 1999;40(3):141-6.

15. Cowie MR, Fahrenbruch CE, Cobb LA, et al. Out-ofhospital cardiac arrest: racial differences in outcome in Seattle. Am 7 Public Health 1993;83(7):955-9.

16. Becker LB, Han BH, Meyer PM, et al. Racial differences in the incidence of cardiac arrest and subsequent survival. The CPR Chicago Project. N Engl 7 Med 1993;329(9): 600-6.

17. Galea S, Blaney S, Nandi A, et al. Explaining racial disparities in incidence of and survival from out-of-hospital cardiac arrest. Am 7 Epidemiol 2007;166(5):534-43.

18. Chu K, Swor R, Jackson R, et al. Race and survival after outof-hospital cardiac arrest in a suburban community. Ann Emerg Med 1998;31(4):478-82.

19. Vadeboncoeur TF, Richman PB, Darkoh M, et al. Bystander cardiopulmonary resuscitation for out-of-hospital cardiac arrest in the Hispanic vs the non-Hispanic populations. Am 7 Emerg Med 2008;26(6):655-60.

20. Shah AS, Bhopal R, Gadd S, et al. Out-of-hospital cardiac arrest in South Asian and white populations in London: database evaluation of characteristics and outcome. Heart 2010;96(1):27-9.

21. Brookoff D, Kellermann AL, Hackman BB, et al. Do blacks get bystander cardiopulmonary resuscitation as often as whites? Ann Emerg Med 1994;24(6):1147-50.

22. Benson PC, Eckstein M, McClung CD, et al. Racial/ethnic differences in bystander CPR in Los Angeles, California. Ethn Dis 2009;19(4):401-6.

23. Iwashyna TJ, Christakis NA, Becker LB. Neighborhoods matter: a population-based study of provision of cardiopulmonary resuscitation. Ann Emerg Med 1999;34 (4 Pt 1):459-68.

24. McNally B, Robb R, Mehta M, et al. Out-of-hospital cardiac arrest surveillance - Cardiac Arrest Registry to Enhance Survival (CARES), United States, October 1, 2005-December 31, 2010. MMWR Surveill Summ 2011;60(8):1-19.

25. Diez Roux AV. Investigating neighborhood and area effects on health. Am 7 Public Health 2001;91(11):1783-9.

26. Ahn KO, Shin SD, Hwang SS, et al. Association between deprivation status at community level and outcomes from outof-hospital cardiac arrest: a nationwide observational study. Resuscitation 2011;82(3):270-6.

27. Braveman PA, Cubbin C, Egerter S, et al. Socioeconomic status in health research: one size does not fit all. $7 A M A$ 2005;294(22):2879-88.

28. Morrison LJ, Nichol G, Rea TD, et al. Rationale, development and implementation of the Resuscitation Outcomes Consortium Epistry-Cardiac Arrest. Resuscitation 2008; 78(2):161-9. 
29. Statistics Canada. Classification of age categories by five-year age groups. Ottawa Statistics Canada; 2010, Available at: http:// www.statcan.gc.ca/concepts/definitions/class-age1-eng.htm (accessed January 31, 2012).

30. Health PCCF + [database]. Statistics Canada - Geography Division. 2010. Available at: http://datalib.chass.utoronto. ca/codebooks/cstdli/pccf.htm (accessed October 25 2011).

31. Statistics Canada. Census tract (CT). Ottawa Statistics Canada; 2009, Available at: http://www12.statcan.ca/censusrecensement/2006/ref/dict/geo013-eng.cfm (accessed August 29, 2011).

32. Nichol G, Stiell IG, Laupacis A, et al. A cumulative meta-analysis of the effectiveness of defibrillator-capable emergency medical services for victims of out-of-hospital cardiac arrest. Ann Emerg Med 1999;34(4 Pt 1):517-25.

33. Leal C, Chaix B. The influence of geographic life environments on cardiometabolic risk factors: a systematic review, a methodological assessment and a research agenda. Obes Rev 2011;12(3):217-30.

34. Pickett KE, Pearl M. Multilevel analyses of neighbourhood socioeconomic context and health outcomes: a critical review. 7 Epidemiol Community Health 2001;55(2):111-22.

35. Matheson FI, LaFreniere MC, White HL, et al. Influence of neighborhood deprivation, gender and ethno-racial origin on smoking behavior of Canadian youth. Prev Med 2011; 52(5):376-80.

36. Matheson FI, White HL, Moineddin R, et al. Drinking in context: the influence of gender and neighbourhood deprivation on alcohol consumption. 7 Epidemiol Community Health 2012;66(6):e4.

37. Winkleby M, Sundquist K, Cubbin C. Inequities in CHD incidence and case fatality by neighborhood deprivation. Am 7 Prev Med 2007;32(2):97-106.

38. Alter DA, Austin PC, Tu JV. Community factors, hospital characteristics and inter-regional outcome variations following acute myocardial infarction in Canada. Can 7 Cardiol 2005;21(3):247-55.

39. Tonne C, Schwartz J, Mittleman M, et al. Long-term survival after acute myocardial infarction is lower in more deprived neighborhoods. Circulation 2005;111(23): 3063-70.

40. Fisher KJ, Li F, Michael Y, et al. Neighborhood-level influences on physical activity among older adults: a multilevel analysis. $\mathcal{F}$ Aging Phys Act 2004;12(1):45-63.

41. Black JL, Macinko J. Neighborhoods and obesity. Nutr Rev 2008;66(1):2-20.
42. Mujahid MS, Diez Roux AV, Morenoff JD, et al. Neighborhood characteristics and hypertension. Epidemiology 2008;19(4):590-8.

43. Auchincloss AH, Diez Roux AV, Mujahid MS, et al. Neighborhood resources for physical activity and healthy foods and incidence of type 2 diabetes mellitus: the multiethnic study of atherosclerosis. Arch Intern Med 2009; 169(18):1698-704.

44. Mair C, Diez Roux AV, Galea S. Are neighbourhood characteristics associated with depressive symptoms? A review of evidence. 7 Epidemiol Community Health 2008; 62(11):940-6, 8 p following 6.

45. Larson NI, Story MT, Nelson MC. Neighborhood environments: disparities in access to healthy foods in the U.S. Am 7 Prev Med 2009;36(1):74-81.

46. Govindarajan A, Schull M. Effect of socioeconomic status on out-of-hospital transport delays of patients with chest pain. Ann Emerg Med 2003;41(4):481-90.

47. Earnest A, Tan SB, Shahidah N, et al. Geographical variation in ambulance calls is associated with socioeconomic status. Acad Emerg Med 2012;19(2):180-8.

48. Grossman DC, Kim A, Macdonald SC, et al. Urban-rural differences in prehospital care of major trauma. 7 Trauma 1997;42(4):723-9.

49. Canada Post. Canada Post - Find a Postal Code. Ottawa Canada Post Corporation; 2011, Available at: http:// www.canadapost.ca/cpotools/apps/fpc/personal/findByCity? execution $=\mathrm{e} 1 \mathrm{~s} 1$ (accessed September 21, 2011).

50. GeoCoder.ca - Location Intelligence Works. Geocorder.ca: Geocoding for North America. Ottawa, Ontario Geocoder.ca; 2011, Available at: http://www.geocoder.ca/ (accessed May 7, 2011).

51. Matheson FI, Dunn JR, Smith KLW, et al. Development of the Canadian Marginalization Index: a new tool for the study of inequality. Can 7 Public Health 2012;103(Suppl. 2): (8): eS12-16.

52. Violent Crime Rate [database]. 2006. Available at: http:// www.stmichaelshospital.com/crich/ (accessed June 7, 2011).

53. Toronto Family Physicians by Census Tract [database]. 2006, Available at: http://www.ices.on.ca (accessed June 23, 2011).

54. Cook NR. Use and misuse of the receiver operating characteristic curve in risk prediction. Circulation 2007; 115(7):928-35.

55. Statistics Canada. Census: data quality verification in place for the 2006 census. Ottawa Statistics Canada; 2009. Available at: http://www12.statcan.ca/census-recensement/ 2006/ref/index-eng.cfm (accessed September 21, 2011). 